\title{
Boeing Man(1964):the origin of realistic algorithmic human figures
}

\author{
Jie Wu \\ College of Design \& Innovation, Tongji University \\ 1239 Siping Road, Shanghai, China \\ wujie@tongji.edu.cn
}

\section{INTRODUCTION}

It is more than forty years since the first wireframe images of the Boeing Man revealed a stylized human pilot in a simulated pilot's cabin. Since then, it has almost become standard to include scenes in Hollywood movies which incorporate virtual human actors. A trait particularly recognizable in the games industry world-wide is the eagerness to render athletic muscular young men, and young women with hour-glass body-shapes, to traverse dangerous cyberworlds as invincible heroic figures.

Tremendous efforts in algorithmic modeling, animation and rendering are spent to produce a realistic and believable appearance of these algorithmic humans. The author traces the development of these realistic human figures worldwide from the very beginning in 1964, when Boeing Man, the first and one of the most significant and iconic images in history of computer graphics was produced.

\section{CASE STUDY}

That is, the 1960s aerospace industry's developments lead to the first algorithmic human's production. At this time, the necessary condition of the Boeing Man's final appearance was the invention of an algorithm to facilitate data-to-picture conversion. The algorithmic human was one of the earliest images to be converted from data to pictorial form. Computer-generated images greatly encouraged the attempts of contemporary visual artists, and computer artists very quickly came forward. The Boeing Man is the first of the few images generated using a computer. Although this form only comprised simple lines, it is still the first attempt made in computer art. In the research of the ergonomics of the human and machine, and modeling of the Boeing Man's form, the method of anthropometrics was applied to gain body proportions.

\section{SIGINIFICANCE}

Up to date, manufacturing, building, fashion and design industries have universally followed the form of the algorithmic human involved in this method. This algorithmic human figure which applied research into aeroplane design ergonomics was not only the first algorithmic human figure but also witness to the birth of computer graphics and at the same time, the clear target of the development of a realistic algorithmic human.

\section{REFERENCES}

Deuber-Mankowsky,Astrid.(2005) Lara Croft: Cyber Heroine. University of Minnesota Press, London.

Dietrich, Frank. (1986) Visual Intelligence: The First Decade of Computer Art (1965-1975). Leonardo Vol. 19, No.2., 159-169.

Fetter, William A. (1965) Computer Graphics in Communication. McGraw-Hill, New York.

Fetter, William A. (1968) Computer Graphics. In 1967 University of Illinois Conference Emerging Concepts in Computer Graphics, edited by Don Secrest and Jurg Nievergelt. W.A.Benjamin,Inc. 397-418.

Fetter, William A. (1982) a Progression of Human Figures Simulated by Computer Graphics. IEEE Computer Graphics and Applications, Vol. 2, No. 9 , 9-13.

Nake, Frieder. (2010) Paragraphs on Computer Art, Past and Present. CAT 2010: Ideas before Their Time, edited by Nick Lambert, Jeremy Gardiner and Francesca Franco, 55-63.

Ratner, Peter. (2003) 3D Human Modeling and Animation. Wiley \& Sons.

Wiedemann, Julius. (2002) Digital Beauties: 2D and 3D CG Digital Models.Taschen. 